\title{
Sustainable Development and The Canadian Forest Sector ${ }^{1}$
}

by J.S. Maini ${ }^{2}$

Forests, covering almost $50 \%$ of Canada's land surface and representing about $10 \%$ of the global forest land, are a predominant feature of the Canadian landscape. The Canadian forest sector ${ }^{3}$ makes an overwhelming contribution to the economic and social well-being of Canadians in all parts of the country. The economic significance of Canadian forests should continue in the future, since the global market demand is projected to increase at the annual rate of approximately $3 \%$ over the next 20 years. Forests also play a vital role in the maintenance of the Canadian environment. The environmental role of these forests ranges from influencing the local and regional climate, checking soil erosion, and providing wildlife habitat, to protecting fisheries habitat, watersheds and the quality of most rivers and lakes in Canada. Consequently, those engaged in the management of the Canadian forest sector have a national as well as global responsibility to maintain the health of Canada's forests through implementation of a policy of sustainable development.

This discussion paper describes the concept of sustainable development and its implications for the Canadian forest sector, and then proposes a framework for translation of this concept into practise.

\section{Sustainable Development: What does it mean in Forestry?}

The term "environmentally sustainable economic development", more commonly known as "sustainable development", has been popularized globally by the Brundtland Commission's report entitled "Our Common Future". ${ }^{4}$ In this report, sustainable development is defined as "economic development that meets the needs of the present without compromising the ability of the future generations to meet their own needs"'.

Since the tabling of the Brundtland report, the term "sustainable development" has captured the imagination of the public as well as of politicians at local, regional, national and international levels. This term has instigated much world wide discussion but most of this has taken place at the conceptual level only. It is described as a desirable objective for all individuals, institutions, economic sectors, societies and indeed for the global community at large. However, there has been little elaboration on how to implement the practice of sustainable development.

From the point of view of the Canadian forest sector, the concept of sustainable development of forest essentially embodies the following three considerations:

- an understanding of the capacity of forest ecosystems to sustain a multiplicity of human uses while maintaining species and ecological diversity;
- managing current and future human activities within the environmental capacity of the forest ecosystems (i.e., respecting "environmental limits"); and

- using or manipulating the forest environment without prejudicing its ecological integrity and use by future generations.

In essence, sustainable development is a process through which the utilization of natural resources, the direction of investment, the orientation of technological development and institutional structures are all continually changing to maintain harmony and to enhance both the current and the future potential of the biosphere to meet human needs and aspirations.

\section{Understanding the Forest Environment}

From an ecological perspective, a forest is a dynamic assemblage of diverse species and a life sustaining system, which has the capability to renew itself. Within a wider context, forests play an important role in local, regional and global cycling of water, carbon, oxygen and nutrients.

Canada's forest land is subjected to a wide range of disturbances which may be aggregated into three categories: natural perturbations, forest sector activities, and non-forest sector industrial and consumptive activities. As with other ecosystems such as grasslands, lakes and the tundra, forest ecosystems are dynamic in that they change and evolve over time, and are frequently subjected to natural perturbations. As long-lived and rather resilient ecosystems, most forests are not ecologically fragile. They are, to a considerable degree, able to withstand a wide range of natural disturbances such as climatic fluctuations (e.g., weather extremes), storms, fires, insects and diseases. These disturbances are integral parts of the forest ecosystems and play a critical role in maintaining their health, species diversity, renewal and rejuvenation capacity.

Forest ecosystems are also subjected to environmental stresses associated with forest sector activities. These activities include the building of access roads, harvesting, manipulation of species and cover types through reforestation, and the use of mechanical, biological and chemical technologies for protection against fire, insects, diseases and competing vegetation.

Furthermore, forests are exposed to stresses caused by non-forest-related human activities. For example, forests serve as a "pollution sink" in that they are receptors of waterborne and airborne pollutants generated through our many industrial and consumptive activities. Also, Canada's forests face the anticipated global warming and other environmental stresses of unprecedented scale.

\section{Managing Human Activities}

For thousands of years, aboriginal peoples had a limited impact on Canada's forest ecosystems. Since the time of settlement by Europeans, forests have played a vital role in economic and social development across Canada and consequently, they have been subjected to a greater degree

\footnotetext{
This paper is a slightly revised version of a Discussion Paper presented to the Canadian Council of Forest Ministers on 6 October 1989 at Niagara Falls, Ontario

Assistant Deputy Minister, Policy, Forestry Canada, Ottawa K1A 1G5.
In this paper, the term "forest sector" includes forests with timber and non-timber values, forest products manufacturing industry and supporting infrastructure.

${ }^{4}$ World Commission on Environment and Development. 1987. Our Common Future. Oxford Univ. Press. XV $+388 \mathrm{pp}$.
} 
of disturbance. While Canada's forests have been utilized for many purposes, a small proportion has been set aside in national and provincial parks and as ecological reserves. Although these forest reserves are protected from consumptive, industrial use and serve as important ecological base lines, they are exposed to airborne pollutants and to the expected global warming.

During the past few decades, the degradation of forest ecosystems (e.g., species composition, soil erosion, destruction of wildlife and fisheries habitats) has increased with the use of progressively powerful technologies employed to harvest and manage our forests. The manufacture of forest products has also been associated with the increase in environmental stresses (e.g., water pollutants). Concurrently, through forest research and by learning from past experiences (both successes and mistakes), we now have an enhanced understanding and application of environmentally appropriate forestry practices and manufacturing technologies. However, there are still considerable gaps in our knowledge of the complex ecological processes and of the limits to which forest ecosystems can be stressed without degradation beyond unacceptable levels, from the environmental, social, economic and aesthetic points of view.

Other non-forest sector production and consumption activities also stress forest ecosystems. These include the generation of airborne pollutants that become deposited on forest lands, often a long distance from their origin. The expected climate change, attributed to the increasing concentration of carbon dioxide and other greenhouse gases in the atmosphere, must also be included in this category of the human-induced stresses. Assured long-term sustainable development of the forest ecosystems will require careful management of production and consumption activities in the forest sector as well as in many other sectors of our economy.

\section{Sustainable Development and Future Generations}

Until recently, societies have placed great emphasis on economic development. However, the past decade has witnessed a heightened awareness of the serious environmental degradation caused by the use of increasingly powerful technologies and by the consumptive demands of a growing world population. Concern for the quality of life is gaining ground, particularly among the economically developed nations, because of an increase in environmental awareness. There is now stronger commitment to environmental stewardship at local, regional and global levels than ever before. The concern for our legacy to future generations is becoming an ethical issue and is being discussed in both public and political forums. Many subscribe to the view that the environment (including its natural resources), is not an asset inherited from the past but one that is held in trust for future generations.

The practice of sustainable development to meet ".....the needs of the present without compromising the ability of the future generations to meet their own needs...." is a challenging task, since both the environmental components (e.g., forest cover types) and human needs (e.g., consumption patterns) change over time. We must, therefore, use the best available knowledge, assess risks involved with various alternatives and make decisions that do not foreclose future options.

As part of our ethical responsibility towards future generations, the following principle governing the sustainable development of forests is proposed:
- Sustainable development of forest land and its multiple environmental values involves maintaining, without unacceptable impairment, the productive and renewal capacities, as well as species and ecological diversity of forest ecosystems.

The level of acceptable limits is determined by the decisions made by individuals and institutions, based on the understanding of socio-economic imperatives. Consequently, the choices and trade-offs are made by the society in terms of risk management and cost of inaction.

\section{Practising Sustainable Development}

All human activities have environmental consequences and the challenge of sustainable development of the forest sector lies in reducing the negative impacts of forest sector and other industrial activities to levels that are within the tolerance limits of forest ecosystems. This would require, for example, adjusting harvesting practices and pulp and paper manufacturing technologies to prevent impairment of fisheries and wildlife habitats. The following five objectives are proposed to meet the challenge of practising sustainable development of the Canadian forest sector:

\section{- Forestry practices:}

1. maintain the productive and renewal capacities, as well as species and ecological diversity of forest ecosystems; and,

2. protect non-timber forest values, such as aesthetics, wildlife and fisheries habitats and watersheds.

- Forest products manufacturing:

3. protect the quality of water, air and land from industrial effluents, at environmentally acceptable levels.

- Protection of forest ecosystems from other industrial and human activities:

4. prevent forest decline by reducing pollutant deposits on forests from other production and consumption activities to levels that are within the assimilative capacity of forest ecosystems and that do not cause unacceptable impairment of ecological integrity, and

5. formulate strategies and action plans to minimize adverse impacts of expected global warming.

\section{Developing Predictive Capacity}

The five objectives mentioned above can only be accomplished if we are able to predict the consequences of various forestry and other industrial activities on forest ecosystems and of forest products manufacturing on the other components of the environment such as water, air and land. Without predictive capacity, we are like accelerating cars at night on a road with curves, and must take care not to over-drive our headlights.

Our ability to predict the environmental consequences, to avoid environmental degradation and to take corrective and curative actions to repair environmental damage, is governed by the following considerations:

- although forest ecosystems are resilient, their productive and renewal capacity and their species and ecological diversity are usually reduced when they are stressed beyond their tolerance limits;

- the level of environmental degradation and the ability of ecosystems to recuperate is generally dependent on the intensity and duration of the stress; 
- the time and cost required to undertake curative actions escalates with the increasing level of ecosystem degradation;

- from ecological, social and economic viewpoints, the policy stance "to anticipate and prevent" is more desirable than "to react and cure;",

- the "anticipate and prevent" mode of action is determined first by our ability to predict the environmental consequences of various forestry and other industrial practises and products manufacturing technologies, and to recognize early warning signals of environmental stress;

- our predictive capacity is currently based largely upon research involving comparative studies of poorly managed or "disturbed" forest land with well managed and with "undisturbed"' (i.e., national parks, ecological reserves) forest land. Carefully designed long-term systematic research, setting aside and protecting ecological reserves as environmental base lines and as biomonitoring sites, and learning from past experience are keys to enhancing our predictive capacity. At present we do possess a limited predictive capacity, but only in certain areas, and have serious gaps in our knowledge and experience in other areas;

- frequently, by the time some of the symptoms, or early warning signals, of environmental stress are visually apparent in biota (e.g., yellowing of needles in forests subjected to prolonged air pollution), it is too late for preventative actions and we are already, at best, in the curative mode. Our present ability to recognize true early warning signals is rather limited; and

- notwithstanding an enhanced ability to predict and recognize early warning signals, nature is full of surprises. Even after using our best judgement, we shall make mistakes. However, we must continue to learn from our past experiences.

\section{Sustained Yield and Sustainable Development of Forests}

Sustained yield is a deeply embedded principle within the forest community. Is sustained yield the same as sustainable development? Yes, but only partly. While sustained yield in forestry is mainly concerned with a perpetual even annual flow of timber for human use, sustainable development of forests is much broader and is concerned with integrated forest management, maintaining the ecological integrity of the forest environment and keeping future options open.

The forests and the forest sector, more than any other profession or resource sector, are well positioned to provide leadership in practising sustainable development in Canada. The forestry community is accustomed to a long-term perspective, it is reasonably knowledgeable on the response of forestry ecosystems to natural and human disturbance, it is comfortable with the sustained yield principle and in a few instances, it has attempted to practice multiple and integrated use of forests. Compared with many other industrial sectors, it is relatively easier for the forest sector to expand its scope from sustained yield to sustainable development of the forest sector. With serious commitment, this transition can be accomplished; it also affords the forestry community an opportunity to exercise leadership to other economic sectors, particularly those engaged in using renewable resources.

\section{The Challenge Ahead}

Canadians are deeply concerned about the quality of their environment, for both present and future generations.
They are now increasingly subscribing to environmental ethics including: "use and not abuse"; "reduce environmental stress"; "recycle"; and "do more with less". The general public is also very concerned about past and current forestry practices and about environmental degradation associated with the manufacturing of some forest products.

The increasing demand for setting aside representative and unique forest types is expected to lead to additional withdrawal of forest land from industrial use. The potential for a resultant local and regional wood supply deficit can be overcome through: a reduction in harvesting waste; more effective wood utilization; more intensive silviculture; as well as using genetically superior trees on selected sites; and recycling of selective forest products. These actions are necessary to maintain our competitiveness and our share in expanding world markets.

The future trends described above are having a direct impact on the activities of the forest community. To achieve the objectives mentioned earlier relating to practising sustainable development of the forest sector, concerted action is required in the following ten areas:

1. make use of the existing knowledge base to practice integrated forest management and establish a national network of demonstration areas;

2. strengthen research to predict the response of forest ecosystems to disturbances associated with natural causes and with human activities, and transfer that knowledge to the forest sector and to the public;

3. develop the capability to recognize early warning signals and indicators of environmental stress in forest and other ecosystems;

4. establish a national system of ecological reserves in Canada's forest land to provide base lines against which the environmental consequences of human activities can be determined;

5. increase forest land productivity in selected areas through improved forest management and forest protection so that more forest land is available for other uses without reducing overall timber flow;

6. reduce waste in forest harvesting operations and in products manufacturing; improve utilization of wood for a variety of end products; encourage recycling where appropriate, to reduce demand for raw materials and to "do more with less";

7. reduce effluents from forest products manufacturing processes to environmentally acceptable levels;

8. reduce pollutants from non-forest sector industrial and consumption activities that cause forest decline through reductions in productivity, renewability, and of species and ecological diversity;

9. undertake systematic policy research to understand decision making processes in the forest sector and to harmonize different economic, environmental, policy and political time horizons; and

10. communicate widely the commitment, policies and programs undertaken by various stake-holders in the forest sector to achieve the objectives of sustainable development.

\section{Epilogue}

The use of increasingly powerful technologies to produce goods and services to meet high consumption demands from an increasing population has led to severe environmental degradation in many parts of the world. The scope and 
complexity of environmental issues has expanded from local and regional to national and global levels. Global environmental issues, such as higher concentration of carbon dioxide and other greenhouse gases and depletion of ozone in the atmosphere, have led to concern for the future of this planet and its inhabitants. Within this context, the concern for future generations is emerging as an ethical issue particularly in the economically developed nations. Environmentally sustainable economic development is seen as a societal value to ensure that we leave a legacy of a healthy environment and adequate natural resources to meet the needs of future generations.

The stewardship of Canada's forest land is a Canadian responsibility from both national and global points of view. The forestry community with its long-term perspective, technical capability and commitment to the sustained yield principle is very well positioned to provide national leadership towards the practice of sustainable forest development. Progress in Canada will also help meet our responsibility to the world.

The forestry profession, the scientific and the policy communities, and the leaders of the Canadian forest sector are becoming increasingly committed to sustainable development of the forest sector and are anxious to contribute their skills and resources to achieve this objective. The political community, such as the Canadian Council of Forest Ministers, now faces the challenge of mobilizing these skills and resources that will make the Canadian forest sector a world class example of sustainable development.

\title{
Appendix I
}

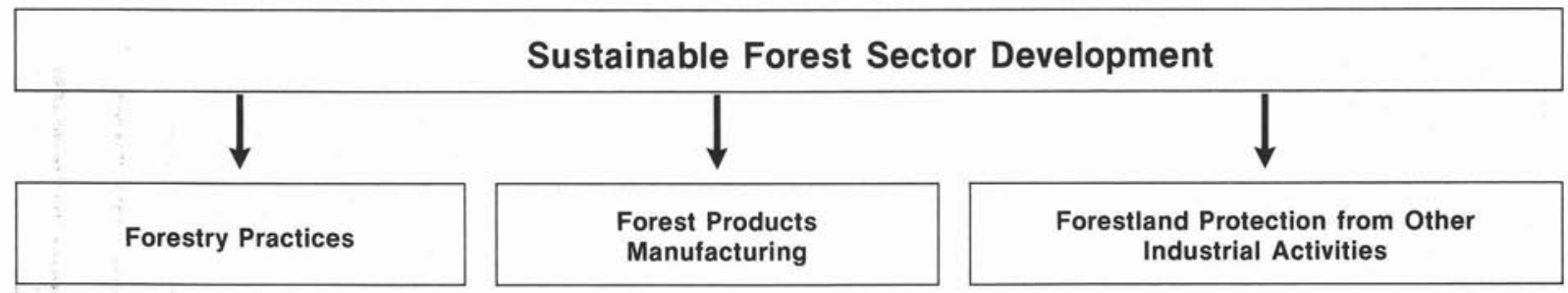

Objectives 1. Maintain productive and renewal capacity, as well as species and ecological diversity of forest ecosystems.

2. Protect other forest environmental values (e.g., wildlife habitats, watersheds).

Actions

- Practice integrated forest management

- Develop capability to predict environmental consequences of human activities through systematic research.

- Develop capability to recognize early warning signals.

- Establish a national network of ecological reserves as baselines.
3. Protect environmental quality of water, air and land receiving effluents from manufacturing activities.

- Use pollution abatement technologies to reduce harmful effluents to acceptable levels.

- Reduce wood waste and improve wood utilization.

- Encourage recycling.
4. Prevent forest decline from harmful effects associated with pollutants and climate change.

5. Formulate strategies to minimize adverse impacts of global warming.

- Determine tolerance limits of forest ecosystems to pollutants through research.

- Participate actively in setting emission control standards and promote innovation to develop pollution abatement technologies.

- Protect and enhance carbon reservoir in forests and forest soils through forest protection and reforestation.

\section{Recent Advances in Pest Management Symposium}

\author{
Sault Ste. Marie, October 22-24, 1990
}

